\title{
基于烷基羧酸的电化学重排环化反应: 吡啶并三唑酮衍生物的合成
}

\author{
马红星 梅天胜* \\ (中国科学院上海有机化学研究所 上海 200032)
}

\section{Electrochemical Rearrangement Cyclization Based on Alkyl Carboxylic Acids: Synthesis of Triazolopyridinone Derivatives}

\author{
Ma, Hongxing Mei, Tiansheng*
}

(Shanghai Institute of Organic Chemistry, Chinese Academy of Sciences, Shanghai 200032)

吡啶并三唑酮衍生物在材料、医药、农药等领域具 有很高的应用价值 ${ }^{[1]}$. 通过吡定并三唑酮和相应的伯烷 基卤化物的 $\mathrm{S}_{\mathrm{N}} 2$ 取代反应可以制备伯烷基取代的吡啶并 三唑酮类衍生物. 然而, 通过常规方法制备手性或大位 阻的吡啶并三唑酮衍生物面临的挑战是消除副反应和 空间位阻. 目前, 仲烷基取代的吡啶并三唑酮衍生物的 合成只有少量报道 ${ }^{[2]}$, 叔烷基取代的吡啶并三唑酮衍生 物的合成尚未见诸报道. 因此, 迫切需要发展一种合成 具有空间位阻的吡啶并三唑酮衍生物的绿色方法.

烷基羧酸是来源丰富, 廉价易得的化学原料, 在有 机合成中是非常重要的合成子. 烷基羧酸可经阳极氧化 发生脱羧反应, 释放碳自由基或者碳正离子进一步发生 偶联反应 ${ }^{[4]}$. 早在 170 年前, Kolbe ${ }^{[3]}$ 在偶联反应中, 采用 电解烷基羧酸原位产生碳自由基, 实现了脱羧偶联. 然 而, 不管是 Kolbe 电解脱羧还是 Barton 酯或 $N$-羟基邻苯 二甲酰亚胺酯的脱羧, 他们所面临的的问题都是反应的 低原子经济性. Baran 团队 ${ }^{[5]}$ 报道了通过电氧化烷基羧酸 产生碳正离子来合成大位阻二烷基梄化合物的新方法.
最近, 浙江工业大学药学院张逢质课题组 ${ }^{[6]}$ 报道了一种 在无金属和氧化剂的电氧化条件下, 经吡啶酰肼分子内 的重排反应制备大位阻吡啶并三唑酮衍生物的方法, 克 服了常规方法的弊端(Scheme 1).

张逢质课题组以吡啶酰肼为模板底物, 对反应条件 进行优化. 当阳极为石墨棒, 阴极为铂片, 媒介为 $(4-\mathrm{Br}-$ $\left.\mathrm{C}_{6} \mathrm{H}_{4}\right)_{3} \mathrm{~N}$, 在 $70{ }^{\circ} \mathrm{C}$ 以 $10 \mathrm{~mA}$ 恒电流电解 $1.8 \mathrm{~h}$, 即通电量 达 $2.2 \mathrm{~F} / \mathrm{mol}$ 时，以高达 $99 \%$ 的收率得到吡啶并三坐酮 产物 1. 随后，该课题组考察了多种结构的烷基羧酸底 物的普适性(Scheme 2). 伯烷基羧酸可以中等至优秀的 收率得到相应的产物, 芳环上有给电子基团时产率更 高. 当仲烷基羧酸和叔烷基羧酸茮位有烷基或苯基时, 能够以优秀的产率获得相应产物. 当叔烷基底物芳香环 上有烷基、环烷基、氟、氯和溴等取代基时, 均可获取 重排的吡啶并三唑酮产物. 药物分子如氟布洛芬等以及 氨基酸或天然产物的后期修饰实验结果表明，该反应表 现出优良的官能团耐受性.

进一步研究表明, 以光学纯烷基羧酸为原料时, 在

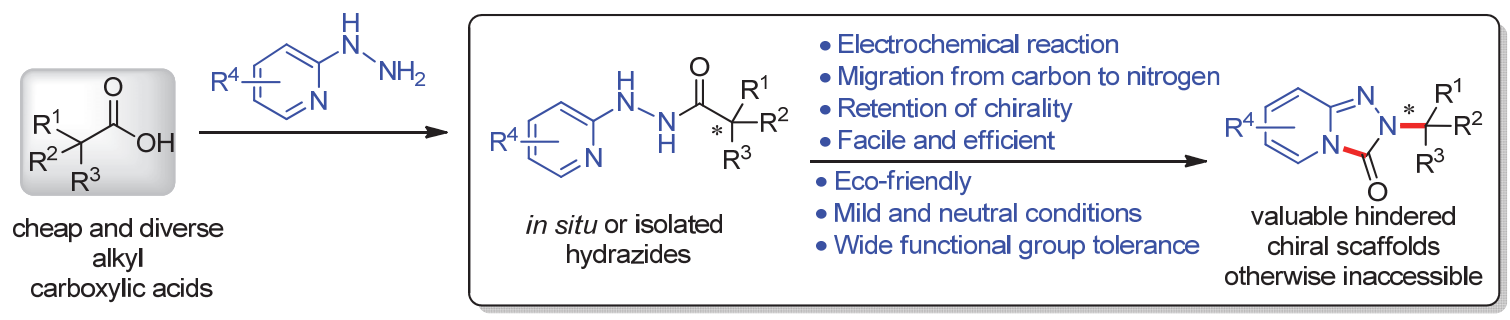

图式 1 电化学重排合成吡啶并三唑酮衍生物

Scheme 1 Synthesis of triazolopyridinones by electrochemical rearrangement

* Corresponding author. E-mail: mei7900@sioc.ac.cn. Published online October 20, 2020. 


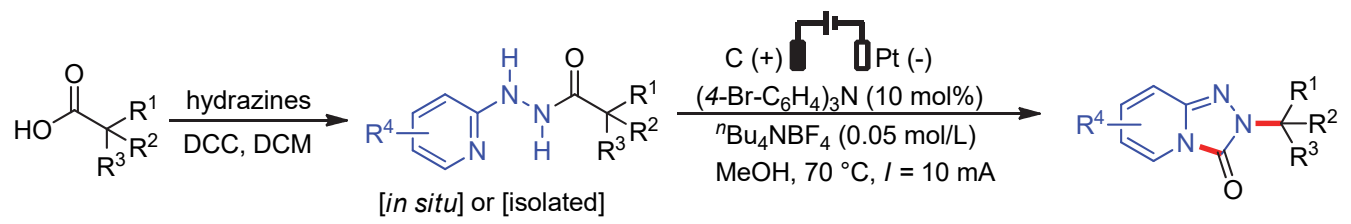

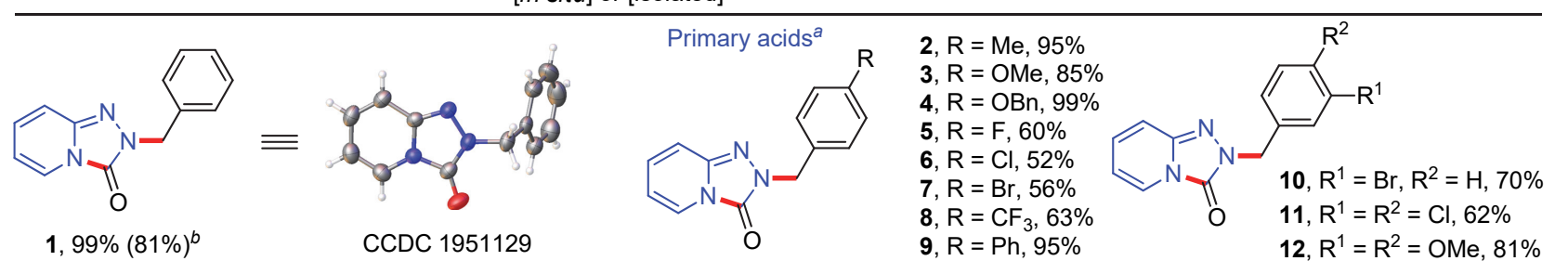

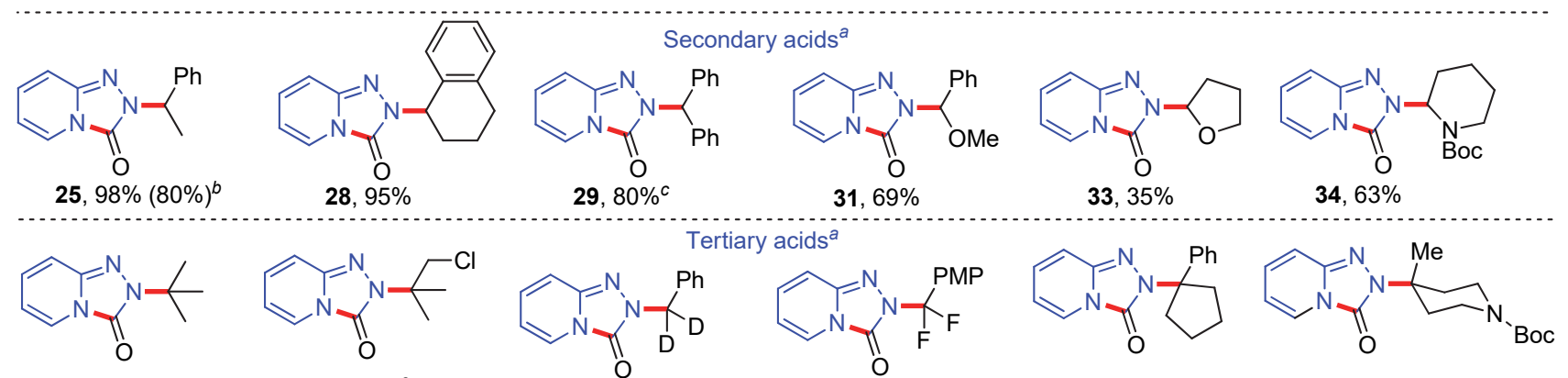

$35,70 \%$

$37,53 \%^{c}$

$38,95 \%$

$39,42 \%$

$42,68 \%$

43, $77 \%$

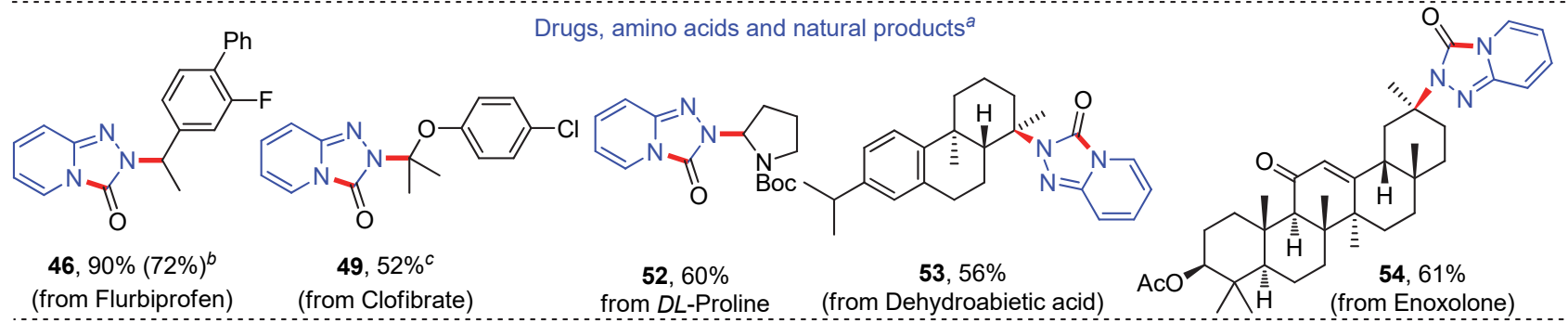

Reaction conditions: ${ }^{a}$ undivided cell, graphite anode, $\mathrm{Pt}$ cathode, hydrazide $(0.3 \mathrm{mmol}), n-\mathrm{Bu}_{4} \mathrm{NBF}_{4}(0.5 \mathrm{mmol}), \mathrm{MeOH}(10 \mathrm{~mL}), 70{ }^{\circ} \mathrm{C}$, $1.8 \mathrm{~h}(2.2 \mathrm{~F} / \mathrm{mol}) ;{ }^{b}$ yield for one-pot reaction with in situ hydrazide; ${ }^{c} 40{ }^{\circ} \mathrm{C}$.

图式 2 部分底物拓展

Scheme 2 Part of the substrate

标准电化学反应条件下可以以高收率和优异的对映选 择性制备相应的光学纯吡啶并三唑酮产物. X 射线单晶 衍射表明该重排反应迁移基团的手性中心是保持的. 该 电化学重排反应是为数不多的可以保留手性化学的例 子. 此外, 张逢质课题组还进行了克级, 甚至十克级放 大反应, 同样可以以良好的收率和优异的 ee 值获得相 应的对映体产物，证明了该反应潜在的实用性.

为研究反应机理, 张逢质课题组进行了一系列控制 实验. 交叉实验证实该反应为分子内的重排; 添加剂 (自由基捕获剂、氢供体)实验和自由基钟实验表明该反 应并非自由基机制. 然而, 将分离到的关键中间体偶氮 化合物在甲醇中回流可以以 $79 \%$ 的收率得到重排产物. 通过对机理研究, 首先酰肼经过电氧化生成 trans-重氮 中间体, 该中间体易于转换为 $c i s$-结构, 之后发生分子 内成环和从碳到氮的 1,2-烷基重排得产物.
综上, 张逢质课题组发展了一种电化学促进的新型 重排环化反应，用于合成常规方法无法获得的大位阻取 代的吡啶并三唑酮, 为进一步的药物篎选和生物活性先 导化合物的发现奠定了基础

\section{References}

[1] Lee, C.-L.; Lee, W.-H; Yang, C.-H. J. Mater. Sci. 2013, 48, 3448.

[2] Silvi, M.; Renzi, P.; Rosato, D.; Margarita, C.; Vecchioni, A.; Bordacchini, I.; Morra, D.; Nicolosi, A.; Cari, R.; Sciubba, F.; Schietroma, D. M. S.; Bella, M. Chem. Eur. J. 2013, 19, 9973.

[3] Kolbe, H. J. Prakt. Chem. 1847, 41, 137.

[4] Tajima, T.; Kurihara, H.; Fuchigami, T. J. Am. Chem. Soc. 2007, 129,6680

[5] Xiang, J.; Shang, M.; Kawamata, Y.; Lundberg, H.; reisberg, S. H.; Chen, M.; Mykhailiuk, P.; Beutner, G.; Collins, M. R.; Davies, A. Bel, M. D.; Gallego, G. M.; Spangler, J. E.; Starr, J.; Yang, S.; Blackmond, D. G.; Baran, P. S. Nature 2019, 573, 398.

[6] Ye, Z.; Wu, Y.; Chen, N.; Zhang, H.; Zhu, K.; Ding, M.; Liu, M.; Li, Y.; Zhang, F. Nat. Commun. 2020, 11, 3628. 